\title{
HYBRID PSOGSA TECHNIQUE FOR SOLVING DYNAMIC ECONOMIC EMISSION DISPATCH PROBLEM
}

\author{
Hardiansyah Hardiansyah*
}

Department of Electrical Engineering, Faculty of Engineering, University of Tanjungpura, Indonesia

\begin{tabular}{l}
\hline ARTICLE INFO: \\
\hline Article history: \\
Received: 18.9 .2018$. \\
Received in revised form: 6.5 .2019$. \\
Accepted: 14.5 .2019$. \\
\hline Keywords: \\
Particle swarm optimization \\
Gravitational search algorithm \\
Dynamic economic emission dispatch \\
Ramp rate limits \\
Prohibited operating zones \\
Valve-point effects \\
\hline DOI: http://doi.org/10.30765/er.40.3.10
\end{tabular}

\section{Introduction}

The fundamental objective of dynamic economic dispatch (DED) problem of electric power generation is to schedule the committed generating unit outputs in order to meet the predicted load demand with minimum operating cost, while satisfying all system inequality and equality constraints $[1,2]$. Therefore, the DED problem is a highly constrained large-scale nonlinear optimization problem. The valve-point effect introduces ripples in the heat-rate curves and makes the objective function non-convex, discontinuous, and with multiple minima [3-5]. The fuel cost function with valve point loadings in the generating units is the accurate model of the DED problem $[6,7]$.

Nowadays, strategically utilizing available resources and achieving electricity at cheap rates without sacrificing the social benefits is of major significance. The environmental pollution plays a major role as it had a major threat on the human

\begin{abstract}
:
In this paper, a new hybrid population-based algorithm is proposed with the combining of particle swarm optimization (PSO) and gravitational search algorithm (GSA) techniques. The main idea is to integrate the ability of exploration in PSO with the ability of exploration in the GSA to synthesize both algorithms' strength. The new algorithm is implemented to the dynamic economic emission dispatch (DEED) problem to minimize both fuel cost and emission simultaneously under a set of constraints. To demonstrate the efficiency of the proposed algorithm, a 5-unit test system is used. The results show the effectiveness and superiority of the proposed method when compared to the results of other optimization algorithms reported in the literature.
\end{abstract}

society. Hence, it became compulsory to deliver electricity at a minimum cost as well as to maintain minimum level of emissions. The lowest emissions are considered as one of the objectives with combined economic and emission dispatch problems, along with the cost economy. Atmospheric pollution due to release of gases such as nitrogen oxides $\left(\mathrm{NO}_{\mathrm{X}}\right)$, carbon dioxide $\left(\mathrm{CO}_{2}\right)$, and sulphur oxides $\left(\mathrm{SO}_{\mathrm{X}}\right)$ into atmosphere by fossil-fuel based electric power stations affects not only humans, but also other forms of life such as birds, animals, plants and fish, while causing global warming too [8-11]. Generating units may have certain prohibited operating zones (POZs) due to faults in the machines themselves or instability concerns or the valve point effect. Hence, considering the effect of valve-points and POZs in generators' cost function makes the economic dispatch a non-convex and non-smooth optimization problem [12].

The dispatching of emission is a short-term option where the emission, in addition to fuel cost objective,

\footnotetext{
* Corresponding author.

E-mail address: hardiansyah@ee.untan.ac.id
} 
is to be optimized. Thus, the DEED problem can be handled as a multi-objective optimization problem and requires only small modification to include emission. Hence, the DEED problem can be converted to a single objective problem by linear combination of various objectives using different weights. The important characteristic of the weighted sum method is that different pareto-optimal solutions could be obtained by varying the weights [13]. In [1416] the static economic dispatch problem with prohibited operating zones has been solved. A number of reported works has considered the prohibited operating zones in the DED problem [1720], however, the emission has not considered in these papers.

PSO is an evolutionary computation technique which is proposed by Kennedy and Eberhart [21, 22]. The main difficulty for classic PSO is its sensitivity to the choice of parameters, and they also premature convergence, which might occur when the particle and group best solutions are trapped into local minimums during the search process. One of the recently improved heuristic algorithms is the GSA based on the Newton's law of gravity and mass interactions. The GSA has been verified as a high quality performance in solving different optimization problems in the literature [23]. The same objective for them is to find the best solution (global optimum) among all possible inputs. To overcome these problem, a heuristic algorithm should be equipped with two major characteristics to ensure finding global optimum. These two main characteristics are exploration and exploitation [24].

The aim of this paper proposes a hybrid PSO-GSA for solving the DEED problem with valve-point effects and prohibited operating zones. The PSO is used to find a near global solution, and the GSA is used as a local search to determine the optimal solution at the final.

\section{Problem formulation}

The objective of the DEED problem is to find the optimal schedule of output powers of online generating units with predicted power demands over a certain period of time to meet the power demand at minimum - both operating costs and emissions simultaneously.

The objective function of the DEED problem can be formulated as following:

$$
\begin{gathered}
F_{T}=w_{1} \cdot \sum_{t=1}^{T} \sum_{i=1}^{N} F_{i, t}\left(P_{i, t}\right)+w_{2} \cdot h \cdot \sum_{t=1}^{T} \sum_{i=1}^{N} E_{i, t}\left(P_{i, t}\right) \\
\quad \text { for } i=1,2, \cdots, N ; \quad t=1,2, \ldots, T
\end{gathered}
$$

where $F_{T}$ is the total operating cost over the whole dispatch period, $T$ is the number of hours in the time horizon, $N$ is the total number of generating units, $w_{1}$ is weighting factor for economic objective such that its value should be within the range 0 and 1 , and $w_{2}$ is the weighting factor for emission objective which is given by $w_{2}=\left(1-w_{1}\right)$, and $h_{i}$ is the price penalty factor. $F_{i, t}\left(P_{i, t}\right)$ and $E_{i, t}\left(P_{i, t}\right)$ are the generation cost and the amount of emission for unit $i$ at time interval $t$, and $P_{i, t}$ is the real power output of generating unit $i$ at time period $t$.

The valve-point effects are taken into consideration in the DEED problem by superimposing the basic quadratic fuel-cost characteristics with the rectified sinusoidal component as follows [12]:

$$
F_{i, t}\left(P_{i, t}\right)=\left(\begin{array}{l}
a_{i} P_{i, t}^{2}+b_{i} P_{i, t}+c_{i}+ \\
\mid e_{i} \times \sin \left(f_{i} \times\left(P_{i, \min }-P_{i, t}\right)\right)
\end{array}\right)
$$

where the constants $a_{i}, b_{i}$, and $c_{i}$ represent generator cost coefficients and $e_{i}$ and $f_{i}$ represent valve-point effect coefficients of the $i$-th generating unit.

Utilization of thermal power plant that consumes fossil fuel is with release of high amounts of $\mathrm{NO}_{\mathrm{X}}$, therefore they are strongly requested by the environmental protection agency to reduce their emissions. The $\mathrm{NO}_{\mathrm{X}}$ emission of the thermal power station having $N$ generating units at interval $t$ in the scheduling horizon is represented by the sum of quadratic and exponential functions of power generation of each unit. The emission due to $i$-th thermal generating unit can be expressed as

$$
E_{i, t}\left(P_{i, t}\right)=\left(\alpha_{i} P_{i, t}^{2}+\beta_{i} P_{i, t}+\gamma_{i}+\eta_{i} \exp \left(\delta_{i} P_{i, t}\right)\right)
$$

where $\alpha_{i}, \beta_{i}, \gamma_{i}, \eta_{i}$ and $\delta_{i}$ are emission coefficients of the $i$-th generating unit.

The minimization of the fuel cost and emission are subjected to the following equality and inequality constraints.

\subsection{Power balance constraint}

The total generated real power should be the same as total load demand plus the total line loss. 


$$
\sum_{i=1}^{N} P_{i, t}=P_{D, t}+P_{L, t}
$$

where $P_{D, t}$ and $P_{L, t}$ are the demand and transmission loss in MW at time interval $t$, respectively.

The transmission loss $P_{L, t}$ can be expressed by using $B$ matrix technique [1] and is defined by (5) as,

$$
P_{L, t}=\sum_{i=1}^{N} \sum_{j=1}^{N} P_{i, t} B_{i j} P_{j, t}
$$

where $B_{i j}$ is the $i j$-th element of the loss coefficient square matrix of size $N$.

\subsection{Generation limits}

The real power output of each generator should lie between minimum and maximum limits.

$$
P_{i, \min } \leq P_{i, t} \leq P_{i, \max }
$$

\subsection{Ramp rate limits}

The ramp-up and ramp-down constraints can be written as (7) and (8), respectively.

$$
\begin{aligned}
& P_{i, t}-P_{i, t-1} \leq U R_{i} \\
& P_{i, t-1}-P_{i, t} \leq D R_{i}
\end{aligned}
$$

where $P_{i, t}$ and $P_{i, t-1}$ are the present and previous real power outputs, respectively. $U R_{i}$ and $D R_{i}$ are the ramp-up and ramp-down limits of unit $i$ (in units of MW/time period).

To consider the ramp rate limits and real power output limits constraint at the same times, therefore, equations (6), (7) and (8) can be rewritten as follows:

$$
\begin{gathered}
\max \left\{P_{i, \min }, P_{i, t-1}-D R_{i}\right\} \leq P_{i, t} \leq \\
\quad \min \left\{P_{i, \max }, P_{i, t-1}+U R_{i}\right\}
\end{gathered}
$$

\subsection{Prohibited operating zones}

The prohibited operating zones are the range of real power output of a generator where the operation causes undue vibration of the turbine shaft bearing caused by opening or closing of the steam valve. The prohibited operating zones of the unit can be described as follows:

$$
P_{i, t} \in\left\{\begin{array}{l}
P_{i, \min } \leq P_{i, t} \leq P_{i, 1}^{l} \\
P_{i, k-1}^{u} \leq P_{i, t} \leq P_{i, k}^{l}, \quad k=2,3, \ldots, p z_{i} \\
P_{i, p z_{i}}^{u} \leq P_{i, t} \leq P_{i, \max }, \quad i=1,2, \ldots, n_{p z}
\end{array}\right.
$$

where $P_{i, k}^{l}$ and $P_{i, k}^{u}$ are the lower and upper boundary of prohibited operating zone of unit $i$, respectively. Here, $p z_{i}$ is the number of prohibited zones of unit $i$ and $n_{p z}$ is the number of units which have prohibited operating zones.

\section{Meta-heuristic optimization}

\subsection{Overview of the PSO}

The particle swarm optimization (PSO) algorithm is introduced by Kennedy and Eberhart based on the social behavior metaphor. In the PSO, a potential solution for a problem is considered as a bird without quality and volume, which is called a particle, flying through a $D$-dimensional space by adjusting the position in search space according to its own experience and its neighbors. In the PSO, the $i$-th particle is represented by its position vector $x_{i}$ in the $D$-dimensional space and its velocity vector $v_{i}$. In each time step $t$, the particles calculate their new velocity, then update their position according to equations (11) and (12) respectively.

$$
\begin{gathered}
v_{i}^{t+1}=w \times v_{i}^{t}+c_{1} \times r_{1} \times\left(\text { pbest }_{i}-x_{i}^{t}\right)+ \\
c_{2} \times r_{2} \times\left(\text { gbest }-x_{i}^{t}\right) \\
x_{i}^{k+1}=x_{i}^{k}+v_{i}^{k+1} \\
w=w_{\text {max }}-\left(\frac{\left(w_{\text {max }}-w_{\text {min }}\right.}{\text { Iter }_{\text {max }}}\right) \times \text { Iter }
\end{gathered}
$$

where $v_{i}^{t}$ is velocity of particle $i$ at iteration $\mathrm{t}, w$ is inertia factor, $c_{1}$ and $c_{2}$ are accelerating factor, $r_{1}$ and $r_{2}$ are positive random number between 0 and 1 , pbest $_{i}$ is the best position of particle $i$, gbest is the best position of the group, $w_{\max }$ and $w_{\min }$ are maximum and minimum of inertia factor, Iter max $_{\text {in }}$ is maximum iteration, $n$ is number of particles.

The PSO begin with randomly placing the particles in a problem space. In each iteration, the velocities of particles are calculated using (11). After defining the 
velocities, position of masses can be calculated as (12). The process of changing particles' position will continue until the stop criteria is reached.

\subsection{Gravitational search algorithm}

The Gravitational Search Algorithm (GSA) is a novel heuristic optimization technique which has been proposed by E. Rashedi et al in 2009 [23]. The basic physical theory based on which GSA is inspired by is the Newton's theory. This algorithm, which is based on the Newtonian physical law of gravity and law of motion, has great potential to be a breakthrough optimization method. In the GSA, consider a system with $N$ agent (mass) in which position of the $i$-th mass is defined as follows:

$$
X_{i}=\left(x_{i}^{1}, \ldots, x_{i}^{d}, \ldots, x_{i}^{n}\right), \quad i=1,2, \ldots, m
$$

where $x_{i}^{d}$ is position of the $i$-th mass in the $d$-th dimension and $n$ is dimension of the search space. At the specific time $t$ a gravitational force from mass $j$ acts on mass $i$, and is defined as follows:

$$
F_{i j}^{d}(t)=G(t) \frac{M_{i}(t) \times M_{j}(t)}{R_{i j}(t)+\varepsilon}\left(x_{j}^{d}(t)-x_{i}^{d}(t)\right)
$$

where $G(t)$ is the gravitational constant at time $t, M_{i}(t)$ and $M_{j}(t)$ are the masses of the objects $i$ and $j$, and $\varepsilon$ is a small constant, and $R_{i j}(t)$ is the Euclidean distance between the two objects $i$ and $j$ objects described as follows:

$$
R_{i j}(t)=\left\|X_{i}(t), X_{j}(t)\right\|_{2}
$$

The masses of the agents are calculated as following by comparison of fitness:

$$
\begin{gathered}
m_{i}(t)=\frac{\operatorname{fit}_{i}(t)-\operatorname{worst}(t)}{\operatorname{best}(t)-\operatorname{worst}(t)} \\
M_{i}(t)=\frac{m_{i}(t)}{\sum_{j=1}^{m} m_{j}(t)}
\end{gathered}
$$

where $f i t_{i}(t)$ represents the fitness value of the agent $i$ at time $t$, best $(t)$ is maximum fitness values of all agents and $\operatorname{worst}(t)$ is the minimum fitness.
Randomly initialized gravitational constant $G(t)$ is decreased according to the time as follows:

$$
G(t)=G_{0} e^{-\alpha \frac{t}{T}}
$$

where $\alpha$ and $G_{0}$ are descending cooefficient and initial value respectively, $t$ is current iteration, and $T$ is maximum number of iterations.

The total force that acts on agent $i$ in the dimension $d$ is described as follows:

$$
F_{i}^{d}(t)=\sum_{\substack{j=1 \\ j \neq i}}^{m} \operatorname{rand}_{j} F_{i j}^{d}(t)
$$

where rand $_{j}$ is a random number interval $[0,1]$.

According to the law of motion, the acceleration of the agent $i$, at time $t$, in the $d$ dimension, $a_{i}^{d}(t)$ is given as follows:

$$
a_{i}^{d}(t)=\frac{F_{i}^{d}(t)}{M_{i i}(t)}
$$

Then, the searching strategy can be described by the next velocity and next position of an agent. The next velocity function is the sum of the current velocity and its current acceleration. The current acceleration is described as the initial acceleration calculated from (21). The initial position is calculated from (14) and the initial speed is determined by producing a zero matrix, which has a $\operatorname{dim} \times N$ dimension (dim: dimension of problem, $N$ : number of agents). Also, the next position function is the sum of the current position and the next velocity of that agent. These functions are shown as follows:

$$
\begin{gathered}
v_{i}^{d}(t+1)=\operatorname{rand}_{i} \times v_{i}^{d}(t)+a_{i}^{d}(t) \\
x_{i}^{d}(t+1)=x_{i}^{d}(t)+v_{i}^{d}(t+1)
\end{gathered}
$$

were rand $_{i}$ is a random number interval $[0,1], v_{i}^{d}(t)$ is the velocity and $x_{i}^{d}(t)$ is the position of an agent at time $t$ in the $d$ dimension.

While solving an optimization problem with the GSA at the beginning of the algorithm, every agent is located at a certain point of the search space, which represents a solution to the problem at every unit of time. Next, according to (22) and (23), masses are 
evaluated, and their next positions are calculated. Then, gravitational constant $G$, masses $M$, and acceleration $\alpha$ are calculated through (17)-(19) and (21) and updated at every time cycle. The search process is stopped after a certain amount of time.

\subsection{The hybrid PSOGSA}

The hybrid PSOGSA approach is an integrated approach between PSO and GSA which combines the ability of social thinking (gbest) in PSO with the local search capability of GSA. In order to combine these algorithms, the updated velocity of agent $i$ can be calculated as follows [24]:

$$
\begin{aligned}
V_{i}(t+1) & =w \times V_{i}(t)+c_{1} \times \operatorname{rand}_{i} \times a_{i}(t)+ \\
c_{2} & \times \operatorname{rand}_{i} \times\left(\text { gbest }^{-} X_{i}(t)\right)
\end{aligned}
$$

where $V_{i}(\mathrm{t})$ is the velocity of agent $i$ at iteration $t, c_{j}$ is a weighting factor, $w$ is a weighting function, rand is a random number between 0 and $1, a_{i}(\mathrm{t})$ is the acceleration of agent $i$ at iteration $t$, and gbest is the best solution so far.

The updating position of the particles at each iteration is as follows:

$$
X_{i}(t+1)=X_{i}(t)+V_{i}(t)
$$

In the hybrid PSOGSA, at the beginning of the algorithm, all agents are randomly initialized. Each mass (agent) is considered as a candidate solution. After initialization, gravitational force, gravitational constant, and resultant forces among the agents are calculated using (15), (19), and (20) respectively.

After that, the acceleration of particles is defined as (21) and updated at every time cycle. After calculating the accelerations and with updating the best solution so far, the velocities of all agents can be calculated using (24). Finally, the positions of the agents are defined as (25). The search process is stopped after a certain amount of time.

\section{The results and discussion}

The feasibility of the proposed method is demonstrated on a 5-unit test system for the given scheduled time duration which is divided into 24 intervals. The 5-unit test system data with nonsmooth fuel cost and emission function, B-loss coefficients, and the load demand for 24 intervals are taken from $[19,25,26]$ and are given in Tables 1, 2, and 3 , respectively.

The algorithms were executed in MATLAB R2015a on a PC with $3.07 \mathrm{GHz}$ CPU and 8-GB RAM. The PSO-GSA parameters used for the simulation are adopted as following: $c_{1}=0.5, c_{2}=1.5, w=\operatorname{rand}[0$, 1], $\alpha=20$ and $G_{0}=100$. The population size $N$ and maximum iteration number $T$ are set to 30 and 100 , respectively, for all case studies.

Tables 4,5 , and 6 , respectively show the optimal solutions of the dynamic economic dispatch (DED, w1 $1=1, w 2=0$ ), dynamic economic emission dispatch (DEED, w1 $=0.5, \quad \mathrm{w} 2=0.5$ ) and pure dynamic emission dispatch (PDED, w1=0, w2=1).

Table 1. Data for the 5-unit system

\begin{tabular}{|l|c|c|c|c|c|}
\hline \multicolumn{1}{|c|}{ Quantities } & Unit 1 & Unit 2 & Unit 3 & Unit 4 & Unit 5 \\
\hline$a_{i}\left(\$ /(\mathrm{MW})^{2} \mathrm{~h}\right)$ & 0.0080 & 0.0030 & 0.0012 & 0.0010 & 0.0015 \\
\hline$b_{i}(\$ / \mathrm{MWh})$ & 2.0 & 1.8 & 2.1 & 2.0 & 1.8 \\
\hline$c_{i}(\$ / \mathrm{h})$ & 25 & 60 & 100 & 120 & 40 \\
\hline$e_{i}(\$ / \mathrm{h})$ & 100 & 140 & 160 & 180 & 200 \\
\hline$f_{i}(\mathrm{rad} / \mathrm{MW})$ & 0.042 & 0.040 & 0.038 & 0.037 & 0.035 \\
\hline$\alpha_{i}\left(\mathrm{lb} / \mathrm{MW}{ }^{2} \mathrm{hr}\right)$ & 0.0180 & 0.0150 & 0.0105 & 0.0080 & 0.0120 \\
\hline$\beta_{i}(\mathrm{lb} / \mathrm{MWhr})$ & -0.805 & -0.555 & -1.355 & -0.600 & -0.555 \\
\hline$\gamma_{i}(\mathrm{lb} / \mathrm{hr})$ & 80 & 50 & 60 & 45 & 30 \\
\hline$\eta_{i}(\mathrm{lb} / \mathrm{hr})$ & 0.6550 & 0.5773 & 0.4968 & 0.4860 & 0.5035 \\
\hline$\delta_{i}(1 / \mathrm{MW})$ & 0.02846 & 0.02446 & 0.02270 & 0.01948 & 0.02075 \\
\hline$P_{i, \min }(\mathrm{MW})$ & 10 & 20 & 30 & 40 & 50 \\
\hline$P_{i, \max }(\mathrm{MW})$ & 75 & 125 & 175 & 250 & 300 \\
\hline$U R_{i}(\mathrm{MW} / \mathrm{h})$ & 30 & 30 & 40 & 50 & 50 \\
\hline$D R_{i}(\mathrm{MW} / \mathrm{h})$ & 30 & 30 & 40 & 50 & 50 \\
\hline $\mathrm{POZ}_{\mathrm{s}-1}$ & {$[2530]$} & {$[4550]$} & {$[6070]$} & {$[95110]$} & {$[80100]$} \\
\hline $\mathrm{POZ}_{\mathrm{s}-2}$ & {$[5560]$} & {$[8090]$} & {$[125140]$} & {$[160180]$} & {$[175200]$} \\
\hline
\end{tabular}


Table 2. B-loss coefficients (5-unit system)

$$
B=\left[\begin{array}{ccccc}
0.000049 & 0.000014 & 0.000015 & 0.000015 & 0.000020 \\
0.000014 & 0.000045 & 0.000016 & 0.000020 & 0.000018 \\
0.000015 & 0.000016 & 0.000039 & 0.000010 & 0.000012 \\
0.000015 & 0.000020 & 0.000010 & 0.000040 & 0.000014 \\
0.000020 & 0.000018 & 0.000012 & 0.000014 & 0.000035
\end{array}\right] \text { per MW }
$$

Table 3. Load demand for 24 hours (5-unit system)

\begin{tabular}{|c|c|c|c|c|c|c|c|}
\hline $\begin{array}{c}\text { Time } \\
(\mathrm{h})\end{array}$ & $\begin{array}{c}\text { Load } \\
(\mathrm{MW})\end{array}$ & $\begin{array}{c}\text { Time } \\
(\mathrm{h})\end{array}$ & $\begin{array}{c}\text { Load } \\
(\mathrm{MW})\end{array}$ & $\begin{array}{c}\text { Time } \\
(\mathrm{h})\end{array}$ & $\begin{array}{c}\text { Load } \\
(\mathrm{MW})\end{array}$ & $\begin{array}{c}\text { Time } \\
(\mathrm{h})\end{array}$ & $\begin{array}{c}\text { Load } \\
(\mathrm{MW})\end{array}$ \\
\hline 1 & 410 & 7 & 626 & 13 & 704 & 19 & 654 \\
\hline 2 & 435 & 8 & 654 & 14 & 690 & 20 & 704 \\
\hline 3 & 475 & 9 & 690 & 15 & 654 & 21 & 680 \\
\hline 4 & 530 & 10 & 704 & 16 & 580 & 22 & 605 \\
\hline 5 & 558 & 11 & 720 & 17 & 558 & 23 & 527 \\
\hline 6 & 608 & 12 & 740 & 18 & 608 & 24 & 463 \\
\hline
\end{tabular}

Table 4. Hourly power schedule obtained from DEED $(w 1=1, w 2=0)$

\begin{tabular}{|c|c|c|c|c|c|c|}
\hline $\mathrm{H}$ & $\mathrm{P}_{1}$ & $\mathrm{P}_{2}$ & $\mathrm{P}_{3}$ & $\mathrm{P}_{4}$ & $\mathrm{P}_{5}$ & Loss \\
\hline 1 & 22.6579 & 98.5398 & 112.6736 & 40.0000 & 139.7599 & 3.6312 \\
\hline 2 & 46.0216 & 98.5394 & 30.0000 & 124.9081 & 139.7597 & 4.2288 \\
\hline 3 & 10.0000 & 97.7067 & 112.6491 & 209.8158 & 50.0000 & 5.1716 \\
\hline 4 & 59.9542 & 98.5399 & 112.6736 & 124.9079 & 139.7599 & 5.8355 \\
\hline 5 & 10.0000 & 94.8374 & 112.0098 & 124.9077 & 222.9279 & 6.6829 \\
\hline 6 & 55.0805 & 98.5395 & 112.6732 & 209.8160 & 139.7588 & 7.8679 \\
\hline 7 & 68.6665 & 98.5397 & 112.6735 & 124.9078 & 229.5195 & 8.3069 \\
\hline 8 & 12.7090 & 98.5398 & 112.6735 & 209.8158 & 229.5196 & 9.2577 \\
\hline 9 & 75.0000 & 100.332 & 175.0000 & 209.8169 & 139.7606 & 9.9147 \\
\hline 10 & 64.0108 & 98.5399 & 112.6736 & 209.8157 & 229.5195 & 10.5595 \\
\hline 11 & 75.0000 & 20.5886 & 175.0000 & 230.7281 & 229.5201 & 10.8367 \\
\hline 12 & 53.2154 & 98.5398 & 175.0000 & 124.9079 & 300.0000 & 11.6632 \\
\hline 13 & 64.0106 & 98.5398 & 112.6736 & 209.8158 & 229.5196 & 10.5595 \\
\hline 14 & 49.6197 & 98.5397 & 112.6735 & 209.8158 & 229.5196 & 10.1683 \\
\hline 15 & 75.0000 & 34.3463 & 114.4072 & 209.8159 & 229.5212 & 9.0906 \\
\hline 16 & 26.4484 & 98.5398 & 112.6737 & 209.8159 & 139.7598 & 7.2375 \\
\hline 17 & 10.0001 & 20.0000 & 110.1488 & 195.0648 & 229.5191 & 6.7327 \\
\hline 18 & 55.0791 & 98.5399 & 112.6734 & 209.8157 & 139.7598 & 7.8679 \\
\hline 19 & 12.7086 & 98.5400 & 112.6736 & 209.8159 & 229.5198 & 9.2577 \\
\hline 20 & 64.0107 & 98.5399 & 112.6735 & 209.8157 & 229.5196 & 10.5595 \\
\hline 21 & 39.3528 & 98.5398 & 112.6736 & 209.8159 & 229.5196 & 9.9016 \\
\hline 22 & 47.1333 & 98.5398 & 112.6735 & 124.9079 & 229.5197 & 7.7742 \\
\hline 23 & 55.2752 & 98.5398 & 30.0000 & 209.8158 & 139.7597 & 6.3905 \\
\hline 24 & 70.0715 & 20.0000 & 112.6735 & 124.9080 & 139.7598 & 4.4127 \\
\hline
\end{tabular}


Table 5. Hourly power schedule obtained from DEED $(w 1=0.5, w 2=0.5)$

\begin{tabular}{|c|c|c|c|c|c|c|}
\hline $\mathrm{H}$ & $\mathrm{P}_{1}$ & $\mathrm{P}_{2}$ & $\mathrm{P}_{3}$ & $\mathrm{P}_{4}$ & $\mathrm{P}_{5}$ & Loss \\
\hline 1 & 61.1248 & 64.8071 & 112.6735 & 124.9079 & 50.0000 & 3.5133 \\
\hline 2 & 67.2893 & 84.1154 & 112.6735 & 124.9079 & 50.0000 & 3.9861 \\
\hline 3 & 75.0000 & 98.5399 & 112.6774 & 124.9080 & 68.6167 & 4.7420 \\
\hline 4 & 74.9999 & 96.2972 & 112.6736 & 124.9079 & 126.9525 & 5.8311 \\
\hline 5 & 74.9995 & 98.5398 & 126.2320 & 124.9159 & 139.7597 & 6.4469 \\
\hline 6 & 74.9999 & 98.5399 & 118.9414 & 183.5086 & 139.7596 & 7.7495 \\
\hline 7 & 75.0000 & 98.5398 & 118.5193 & 202.4505 & 139.7594 & 8.2690 \\
\hline 8 & 74.9999 & 98.5398 & 145.2560 & 204.3880 & 139.7595 & 8.9432 \\
\hline 9 & 74.9999 & 100.331 & 175.0000 & 209.8158 & 139.7608 & 9.9147 \\
\hline 10 & 75.0000 & 114.719 & 175.0000 & 209.8158 & 139.8306 & 10.3593 \\
\hline 11 & 75.0000 & 125.000 & 175.0000 & 209.8206 & 146.0384 & 10.8590 \\
\hline 12 & 75.0000 & 125.000 & 175.0000 & 211.3129 & 165.1379 & 11.4508 \\
\hline 13 & 74.9999 & 114.763 & 175.0000 & 209.8166 & 139.7737 & 10.3596 \\
\hline 14 & 75.0000 & 100.331 & 175.0000 & 209.8157 & 139.7600 & 9.9147 \\
\hline 15 & 75.0000 & 98.5396 & 155.7470 & 193.8476 & 139.7597 & 8.8939 \\
\hline 16 & 74.9998 & 98.5396 & 148.7354 & 124.9079 & 139.7586 & 6.9413 \\
\hline 17 & 74.9995 & 98.5399 & 126.2392 & 124.9085 & 139.7598 & 6.4469 \\
\hline 18 & 75.0000 & 98.5400 & 175.0000 & 127.3262 & 139.7597 & 7.6259 \\
\hline 19 & 74.9999 & 98.5398 & 173.0506 & 176.4919 & 139.7597 & 8.8419 \\
\hline 20 & 74.9999 & 114.785 & 175.0000 & 209.8158 & 139.7634 & 10.3597 \\
\hline 21 & 75.0000 & 98.5396 & 173.2934 & 203.0181 & 139.7598 & 9.6108 \\
\hline 22 & 75.0000 & 98.5400 & 174.3446 & 124.9079 & 139.7597 & 7.5523 \\
\hline 23 & 74.9992 & 96.5785 & 112.6735 & 124.9079 & 123.6070 & 5.7660 \\
\hline 24 & 74.9995 & 98.4382 & 112.6741 & 124.9078 & 56.5128 & 4.5324 \\
\hline & Cost=45702.6001\$, Emission=18267.17881b, Loss=188.9105 MW \\
\hline \multicolumn{7}{|c}{} \\
\hline
\end{tabular}

Table 6. Hourly power schedule obtained from DEED $(w 1=0, w 2=1)$

\begin{tabular}{|c|c|c|c|c|c|c|}
\hline $\mathrm{H}$ & $\mathrm{P}_{1}$ & $\mathrm{P}_{2}$ & $\mathrm{P}_{3}$ & $\mathrm{P}_{4}$ & $\mathrm{P}_{5}$ & Loss \\
\hline 1 & 54.6785 & 58.2356 & 116.5718 & 110.5981 & 73.3639 & 3.4480 \\
\hline 2 & 58.0672 & 62.3836 & 121.8514 & 117.9818 & 78.6016 & 3.8854 \\
\hline 3 & 63.5261 & 69.0803 & 130.2207 & 129.7503 & 87.0639 & 4.6413 \\
\hline 4 & 71.1206 & 78.4296 & 141.5517 & 145.8017 & 98.8901 & 5.7936 \\
\hline 5 & 74.9998 & 83.2693 & 147.2394 & 153.9052 & 105.0170 & 6.4307 \\
\hline 6 & 75.0000 & 93.5801 & 158.7930 & 170.2750 & 118.0066 & 7.6547 \\
\hline 7 & 74.9999 & 97.2850 & 162.9871 & 176.3836 & 122.4682 & 8.1238 \\
\hline 8 & 75.0000 & 103.100 & 169.0769 & 185.3854 & 130.3109 & 8.8812 \\
\hline 9 & 75.0000 & 111.392 & 175.0000 & 197.9016 & 140.6181 & 9.9138 \\
\hline 10 & 75.0000 & 115.343 & 175.0000 & 203.6178 & 145.3780 & 10.3381 \\
\hline 11 & 75.0000 & 119.609 & 175.0000 & 209.8641 & 151.3608 & 10.8338 \\
\hline 12 & 75.0000 & 125.000 & 175.0000 & 217.2826 & 159.1889 & 11.4716 \\
\hline 13 & 75.0000 & 115.673 & 175.0000 & 203.0533 & 145.6120 & 10.3376 \\
\hline 14 & 75.0000 & 111.430 & 175.0000 & 197.7360 & 140.7395 & 9.9134 \\
\hline 15 & 75.0000 & 103.135 & 169.2397 & 185.4858 & 130.0167 & 8.8817 \\
\hline 16 & 75.0000 & 87.7294 & 152.3596 & 161.2403 & 110.6262 & 6.9555 \\
\hline 17 & 75.0000 & 83.2655 & 147.2436 & 153.9050 & 105.0166 & 6.4307 \\
\hline 18 & 75.0000 & 93.4857 & 158.8899 & 170.3447 & 117.9344 & 7.6547 \\
\hline 19 & 75.0000 & 103.061 & 169.3818 & 185.1451 & 130.2864 & 8.8804 \\
\hline
\end{tabular}




\begin{tabular}{|l|c|c|c|c|c|c|}
\hline 20 & 75.0000 & 115.465 & 175.0000 & 203.0490 & 145.8251 & 10.3366 \\
\hline 21 & 75.0000 & 108.579 & 174.8244 & 194.0691 & 137.1487 & 9.6180 \\
\hline 22 & 75.0000 & 92.8374 & 158.1129 & 169.5503 & 117.0779 & 7.5784 \\
\hline 23 & 70.7033 & 77.9152 & 140.9393 & 144.9310 & 98.2386 & 5.7274 \\
\hline 24 & 61.8833 & 67.0629 & 127.7207 & 126.2266 & 84.5138 & 4.4073 \\
\hline \multicolumn{6}{|c|}{ Cost $=51953.9046 \$$, Emission $=17852.9791 \mathrm{lb}$, Loss $=188.1381 \mathrm{MW}$} \\
\hline
\end{tabular}

Table 7. Comparison results for 5-unit system

\begin{tabular}{|c|l|l|l|c|}
\hline Weight & Method & Cost $(\$)$ & Emission (lb) & Run time (s) \\
\hline \multirow{3}{*}{ w1=1; w2=0 } & PSO [25] & 47852 & 22405 & - \\
\cline { 2 - 5 } & DE-SQP [26] & 45590 & 23567 & - \\
\cline { 2 - 5 } & PSOGSA & 42853.3394 & 22087.8872 & 40.322 \\
\hline \multirow{3}{*}{ w1=0.5; w2=0.5 } & PSO [25] & 50893 & 20163 & - \\
\cline { 2 - 5 } & DE-SQP [26] & 46625 & 20527 & - \\
\cline { 2 - 5 } & PSOGSA & 45702.6001 & 18267.1788 & 40.614 \\
\hline \multirow{3}{*}{ w1=0; w2=1 } & PSO [25] & 53086 & 19094 & - \\
\cline { 2 - 5 } & DE-SQP [26] & 52611 & 18955 & - \\
\cline { 2 - 5 } & PSOGSA & 51953.9046 & 17852.9791 & 40.514 \\
\hline
\end{tabular}

Tables 4 and 6 show that the cost is $42,853.3394 \$$ under DED but it increases to $51,953.9046$ under PDED, and emission obtained from DED is $22,087.8872 \mathrm{lb}$ but decreases to $17,852.9791 \mathrm{lb}$ under PDED.

Table 5 shows that the cost is $45,702.6001 \$$ which is more than 42,853.3394 \$ (in case of DED) and less than 51,953.9046 \$ (in case of PDED), and emission is $18,267.1788 \mathrm{lb}$ which is less $22,087.8872 \mathrm{lb}$ (in case of DED) and more than 17,852.9791 lb (in case of PDED).

Table 7 shows that, the efficiency of the proposed method compare to other methods for DEED problem at different weighting factors. It appears that both fuel cost and emission are less than the other methods reported in the literature. The table also shows the running time for each step of the process.

\section{Conclusion}

In this paper, a new hybrid PSOGSA technique has been applied to solve the non-convex DEED problem of generating units considering the valve-point effects, prohibited operation zones, ramp rate limits and transmission loss. The proposed technique has provided the best solution in the 5-unit test systems and better solution than the previous studies reported in the literature. The simulation results show the high performance of the PSOSGA algorithm on minimizing fuel cost and reduced emission. The analyses of the results are very promising since the main objectives of the proposed technique were achieved. Future studies will focus on multiobjective economic emissions power dispatch considering renewable energy.

\section{References}

[1] Wood, A. J., Wollenberg, B. F.: (1996). Power Generation, Operation, and Control, $2^{\text {nd }}$ ed., John Wiley and Sons, New York.

[2] Xia, X., Elaiw, A. M.: Optimal Dynamic Economic Dispatch of Generation: A Review, Electric Power Systems Research, 80 (2010), 8, 975- 986.

[3] Yuan, X., Su, A., Yuan, Y., Nie, H., Wang, L.: An Improved PSO for Dynamic Load Dispatch of Generators with Valve-Point Effects, Energy, 34 (2009), 67-74.

[4] Victoire, T. A. A., Jeyakumar, A. E.: Deterministically Guided PSO for Dynamic Dispatch Considering Valve-Point Effects, Electric Power Systems Research, 73 (2005), 3, 313-322.

[5] Gaing, Z. L.: Constrained Dynamic Economic Dispatch Solution Using Particle Swarm Optimization, IEEE Power Engineering Society General Meeting, 1 (2004), 153-158.

[6] Basu, M.: Artificial Immune System for Dynamic Economic Dispatch, International Journal of Electrical Power \& Energy Systems, 33 (2011), $1,131-136$. 
[7] Benhamida, F., et al.: A solution to dynamic economic dispatch with prohibited zones using a Hopfield neural network, $7^{\text {th }}$ International Conference on Electrical and Electronic Engineering, Bursa, Turkey, 1-4 December 2011, 423-427.

[8] Abido, M. A.: Environmental/Economic Power Dispatch Using Multi-Objective Evolutionary Algorithms, IEEE Transactions on Power Systems, 18 (2003), 4, 1529-1537.

[9] Basu, M.: Evolutionary Programming-Based Goal-Attainment Method for Economic Emission Load Dispatch with Non-Smooth Fuel Cost and Emission Level Functions, Journal of The Institution of Engineers (India), 86 (2005), 95-99.

[10] Guvenc, U.: Combined Economic Emission Dispatch Solution Using Genetic Algorithm Based on Similarity Crossover, Sci. Res. Essay, 5 (2010), 17, 2451-2456.

[11] Sonmez, Y.: Multi-Objective Environmental/ Economic Dispatch Solution with Penalty Factor Using Artificial Bee Colony Algorithm, Sci. Res. Essay, 6 (2011), 13, 2824-2831.

[12] Park, J. B., Lee, K. S., Shin, J. R., Lee, K. Y.: A Particle Swarm Optimization for Economic Dispatch with Nonsmooth Cost Functions, IEEE Transactions on Power Systems, 20 (2005), 1, 34-42.

[13] Abido, M. A.: A Novel Multiobjective Evolutionary Algorithm for Environmental/ Economic Power Dispatch, Electric Power Systems Research, 65 (2003), 71-81.

[14] Yang, H. T., Yang, P. C., Huang, C. L.: Evolutionary Programming Based Economic Dispatch for Units with Non-Smooth Fuel Cost Functions, IEEE Transactions on Power Systems, 11 (1996), 1, 112-118.

[15] Gaing, Z. L.: Particle Swarm Optimization to Solving the Economic Dispatch Considering the Generator Constraints, IEEE Transactions on Power Systems, 18 (2003), 3, 1187-1195.

[16] Duman, S., Guvenc, U., Yorukeren, N.: Gravitational Search Algorithm for Economic Dispatch with Valve-Point Effects, International Review of Electrical Engineering, 5 (2010), 6, 2890-2895.

[17] Balamurugan, Subramanian, S.: An Improved
Differential Evolution Based Dynamic Economic Dispatch with Nonsmooth Fuel Cost Function, Journal of Electrical Systems, 3 (2007), 3, 151-161.

[18] Mohammadi-ivatloo, B., Rabiee, A., Ehsan, M.: Time Varying Acceleration Coefficients IPSO for Solving Dynamic Economic Dispatch with Non-Smooth Cost Function, Energy Conversion and Management, 56 (2012), 175-183.

[19] Mohammadi-ivatloo, B., Rabiee, A., Soroudi, A., Ehsan, M.: Imperialist Competitive Algorithm for Solving Non-Convex Dynamic Economic Power Dispatch, Energy, 44 (2012), 228-240.

[20] Rajkumari Batham, Kalpana Jain, Manjaree Pandit,: Improved Particle Swarm Optimization Approach for Nonconvex Static and Dynamic Economic Power Dispatch, International Journal of Engineering, Science and Technology, 3 (2011), 4, 130-146.

[21] Kennedy, J., Eberhart, R.: Particle Swarm Optimization, in Proc. IEEE Int. Conf. NEURAL NETWORKS (ICNN'95), 1995, Perth, Australia, Vol. IV, pp. 1942-1948.

[22] Shi, Y., Eberhart, R.: A Modified Particle Swarm Optimizer, in Proceedings of IEEE International Conference on EVOLUTIONARY COMPUTATION, 1998, Anchorage, Alaska, pp. 69-73.

[23] Rashedi, E, Nezamabadi-pour, H., Saryazdi, S.: GSA: A Gravitational Search Algorithm, Information Sciences, 179 (2009), pp. 22322248.

[24] Mirjalili, S., Siti Zaiton Mohd Hashim.: A New Hybrid PSOGSA Algorithm for Function Optimization, IEEE International Conference on Computer and Information Application (ICCIA 2010), 2010, pp. 374-377.

[25] Basu, M.: Particle Swarm Optimization Based Goal-Attainment Method for Dynamic Economic Emission Dispatch, Electric Power Components and Systems, 34 (2006), 10151025.

[26] Shehata, A. M., Elaiw, A. M.: Hybrid DE-SQP for Solving Dynamic Economic Emission Dispatch with Prohibited Operating Zones, International Journal of Scientific \& Engineering Research, 6 (2015), 10, 1136-1141. 